\section{CFCs active}

SIR - Surely the description of CFCs as "greenhouse neutral" is misleading. Although recent research suggests that these gases may cause only a slight change in the total amount of outgoing infrared radiation trapped by the Earth's atmosphere ${ }^{2}$, the heat will be trapped at different altitudes from those in the unperturbed atmosphere. This is not a neutral process, and if, for example, more heat is trapped in the lower atmosphere while the upper atmosphere cools it could stimulate enhanced convection and bring unpredictable changes in weather patterns.

John Gribbin

Rose Cottage, Piddinghoe,

Newhaven BN9 9AT, UK

1. Montgomery, K., Nature, 356. 738 (1992).

2. Ramaswamy, V. Schwarzkopf, M. D., \& Shine, K. P., Nature, 355, 810-812 (1992).

\section{Running in the family}

SIR - We were interested to read the recent correspondence ${ }^{1}$ about the sex ratio of artists' offspring, as we have just finished a survey into the secondary sex ratio of male distance runners' children, carried out because there is some anecdotal evidence to suggest that distance athletes father more daughters than sons.

Runners were approached at club training evenings and at races, in and around Glasgow. They were asked various questions regarding their physical activity around the time of conception of each of their children. The information sought included weekly training mileage, training intensity, whether heavily involved in other sports, and if they had any time off training due to injury.

We obtained data from 139 runners who were training around the time of the conception of at least one of their children, and from 66 males who took up running only after their children were born.

The results we found when the data were grouped by training mileage are summarized below:

$\begin{array}{llllll}\begin{array}{l}\text { Miles per } \\ \text { week }\end{array} & \text { Nil } & 0-30 & 30-50 & 50-70 & 70+ \\ \text { Sex ratio } & 0.62 & 0.63 & 0.40 & 0.58 & 0.53\end{array}$

Total no.

of children $\begin{array}{lllll}181 & 80 & 116 & 60 & 36\end{array}$

Using the formula in ref. 1 , the sex ratios of children born to fathers who were not running at the time of conception, and to those completing 0-30 and 30-50 miles per week were all signifi- cantly different from the normal of 0.514 $(P<0.001, \quad P<0.03, \quad P<0.006$ respectively).

None of the following could be related to sex ratio in any manner: training intensity, occupation (manual versus non-manual), paternal age, time between marriage and conception, and whether the father felt he was on a winning or losing streak when the baby was conceived.

Although we were relying on the athletes' memories for their weekly mileages, the vast majority were very precise about their training regime at the time of conception. If there were some inaccuracies in the reporting of amount of training, it is difficult to see how these could appreciably affect the results.

The high sex ratio among the children born to fathers who later took up running could perhaps be due to their being more likely to become involved in the sport if their child was a son. Similar reasoning might be applied to those running more to keep fit rather than for competition. Thus they also may have been more likely to become involved if they had sons.

Many distance runners have lowered testosterone levels ${ }^{3}$, and the secondary sex ratio has been linked with parental testosterone levels at the time of conception ${ }^{4}$. Is this the reason for our result of a low sex ratio in middle distance runners? Do athletes covering distances in excess of 50 miles per week have higher than average testosterone levels and so father a greater proportion of sons? Further work in this area is desirable, not least to increase the numbers in our survey.

\section{E. Crawford}

D. Gilmore

\section{W. H. James}

University of Glasgow,

Institute of Physiology,

Glasgow G12 8QQ, UK

1. Beck, R. A. Nature 356, 189 (1992)

2. Moore, D. H. \& Gledhill, B. L. Fertil. Steril. 50, 21-25 (1988).

3. Cumming, D. C. Sports Med. 7, 1-17 (1989).

4. James, W. H. J. theor. Biol. 143, 555-564 (1990).

SIR - R. A. Beck ${ }^{1}$ proposes an observed sex ratio among the offspring of "artists" expressed as a small but significant male excess.

The sex-ratio is not a stable value, showing marked variation between populations as well as significant secular change. In the United Kingdom, it is currently the lowest recorded since 1933, with a steady decline since 1978 culminating in 1988 with a deficiency of males at 104.8 live births per 100 females, giving a sex-proportion of 0.5117 (ref. 2).

Converting Beck's figures to the more usually adopted convention of sex proportion (the proportion of the total population who are male) his value for "artists" is 0.5278 and for "others in Who's Who" 0.5112 .

There are many variables known to affect the sex ratios but one of the most significant is birth order ${ }^{3}$, with a declining sex ratio (fewer male births) as family size increases. Although slightly different from Novitski and Sandler's US figures, this results in the United Kingdom in a sex proportion of 0.5294 for families of two children and 0.5271 for families of three children ${ }^{4}$, corresponding closely with Beck's value of 0.5278 for artists.

If Beck looks at the family size as well as the years of birth, and thus birth order of his artists group, he may well discover family sizes of between two and three - possibly the maximum number that can be accommodated in an artist's garret!

\section{R. C. Connolly}

Department of Human Anatomy

\& Cell Biology, PO Box 147, University of Liverpool L69 3BX, UK

1. Beck, R. A. Nature 356, 189 (1992).

2. Shaw, C. Poput. Stud. 57, 26-29 (1989).

3. Novitski, E. \& Sandler, L. Ann. Human Genet. 21 123-31 (1956).

4. Connolly, R. C. (unpublished data).

\section{British science}

SIR - In their recent letter ${ }^{1}$, Martin and Irvine merely rehash their old relative studies, and make no attempt to address the evidence of absolute British expansion in science. I shall therefore point out only that a relative British scientific decline is not only inevitable, it is actually desirable if it means that previously poor countries are catching up ${ }^{2}$; as long as British science grows absolutely at its current rates, the needs of the nation at large will have been more than met.

Let me correct two mistatements of Martin and Irvine ${ }^{1}$. (1) My assertions have not been laid to rest by references 3-7 as detailed in my published rebuttal $^{8}$. (2) I did not restrict my analysis of the Institute for Scientific Information's most cited papers to 1983 and 1984 (see the legend to Table 3 in ref. 9), but the issues of Current Contents for 1990 and 1991 that cover citations in the late 1980s were published before my own paper was submitted to Scientometrics ${ }^{9}$. Terence Kealey

Department of Clinical Biochemistry, Addenbrooke's Hospital,

Hills Road, Cambridge CB2 2QR, UK

\footnotetext{
1. Martin, B. R. \& Inine, J. Nature 355, 760 (1992). Kealey T Science Technol. Policy 4, 8-14 (1991) 3. Roberts, D. H. Nature 350,550 (1991).

4. Ashall, F. \& Goate, A. M. Nature 350, 550 (1991)

5. Collins, P. Nature 351, 8 (1991)

6. Humphreys, C. Nature 351, 513 (1991)

7. Mulvey, J. Nature 351, 513 (1991).

8. Kealey, T. Nature 352, 466 (1991)
} 